\title{
Osteitis of the radius following Bacillus Calmette-Guérin vaccination at birth: a case report
}

\author{
Abdelmoneim E. M. Kheir ${ }^{1,4^{*}}$, Salah A. Ibrahim', Azza Abdelsatir ${ }^{2}$ and Mustafa E. Bahar ${ }^{3}$
}

\begin{abstract}
Background: The Bacillus Calmette-Guérin vaccine, which is used for the prevention of tuberculosis, is considered protective against the severe forms of childhood tuberculosis. However, some serious adverse reactions including osteitis of the long bones can occur.

Case presentation: We report a case of an 18-month-old Sudanese girl who presented at the age of 3 months with swelling of her left forearm following Bacillus Calmette-Guérin vaccination administered at birth. Radiological and histological investigations confirmed tuberculous osteitis of the distal radius. She responded very well to antituberculous treatment with complete healing at follow-up visits. To the best of our knowledge this is the first case report of osteitis of the radius following Bacillus Calmette-Guérin vaccination described from Sudan.

Conclusions: Bacillus Calmette-Guérin osteitis, although rare, should be considered a possible complication of the Bacillus Calmette-Guérin vaccination, and early diagnosis and treatment are essential.
\end{abstract}

Keywords: Osteitis of radius, Tuberculosis, BCG, Vaccine, Sudan, Case report

\section{Background}

The Bacillus Calmette-Guérin (BCG) vaccine, which contains a live attenuated strain of Mycobacterium bovis, is considered to be protective against severe forms of childhood tuberculosis including tuberculous meningitis [1]. Although it is a relatively safe vaccine, some serious adverse reactions were reported. The most frequent complications are local subcutaneous abscess or suppurative regional lymphadenitis. Other systemic complications include musculoskeletal lesions, non-fatal disseminated infection, and fatal disseminated disease [2].

Osteitis following BCG vaccination is extremely rare, with an incidence of $0.39 / 1,000,000$, depending on the bacillus used [3]. The lesions are localized to the metaphysis or epiphysis of long bones [4]. Ibrahim et al. had reported a case of median nerve compression following

\footnotetext{
* Correspondence: moneimkheir62@hotmail.com

${ }^{1}$ Department of Paediatrics and Child Health, Faculty of Medicine, University of Khartoum, Khartoum, Sudan

${ }^{4}$ Department of Paediatrics and Child Health, Faculty of Medicine, University of Khartoum and Soba University Hospital, P.O. Box 102, Khartoum, Sudan Full list of author information is available at the end of the article
}

BCG vaccination that resolved after drainage of the abscess [5]. There are reports that osteitis following BCG vaccination occurs in places where neonates are vaccinated with MPB70-high-producer BCG substrains. In countries like Finland, Sweden, Czech Republic, and Slovakia, the incidence of osteitis varies, depending on the strain used for vaccination [6]. Most cases of osteitis following BCG vaccination were believed to be caused by hematogenous dissemination of BCG strains due to the abundant blood supply at the time of the initial bacteremia [7].

We report a case of an 18-month-old Sudanese girl who presented at the age of 3 months with swelling of her left forearm following BCG vaccination that was given at birth. Radiological and histological investigations confirmed tuberculous osteitis of the radius. She responded very well to antituberculous treatment with complete healing at follow-up visits. To the best of our knowledge this is the first case report of osteitis of the radius following BCG vaccination described from Sudan. 


\section{Case presentation}

An 18-month-old Sudanese girl, who had a normal birth history and an uneventful early neonatal period, received the BCG vaccine at birth on her left forearm as part of the routine vaccination schedule in Sudan. There was no history of contact with tuberculosis. At the age of 2 months, she developed a swelling at the BCG site which was tender but there was no discharge; a few weeks later her whole left arm became swollen with reduced movement. There were no lymph nodes enlargements. She was seen at a surgery where an abscess was drained and she was prescribed antibiotics. She continued to be febrile and developed discharging sinus at the site of the wound. Further radiological assessment of her left wrist joint showed a well-defined metaphyseal lytic lesion with partially sclerotic margin and narrow zone of transition not crossing the physis, and soft tissue opacity was noted indicating soft tissue component. These findings were compatible with osteitis (Fig. 1). Her complete blood count was normal, erythrocyte sedimentation rate (ESR) was $5 \mathrm{~mm} /$ hour, and her C-reactive protein (CRP) was negative. A chest X-ray (CXR) was also normal.

At this stage the lesion was drained once again and a tissue biopsy showed multiple histiocytes and giant cells with foci of necrosis consistent with tuberculous granuloma (Fig. 2). She was started on antituberculous

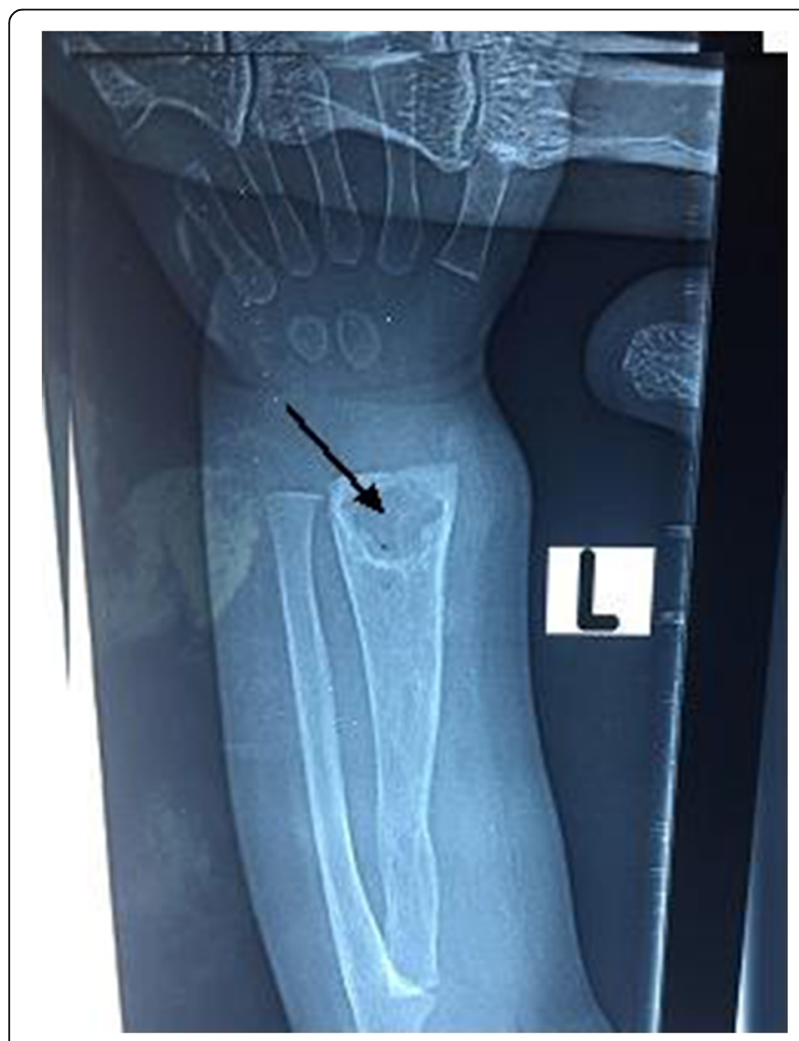

Fig. 1 A well-defined metaphyseal lytic lesion with partially sclerotic margin compatible with osteitis (arrow)

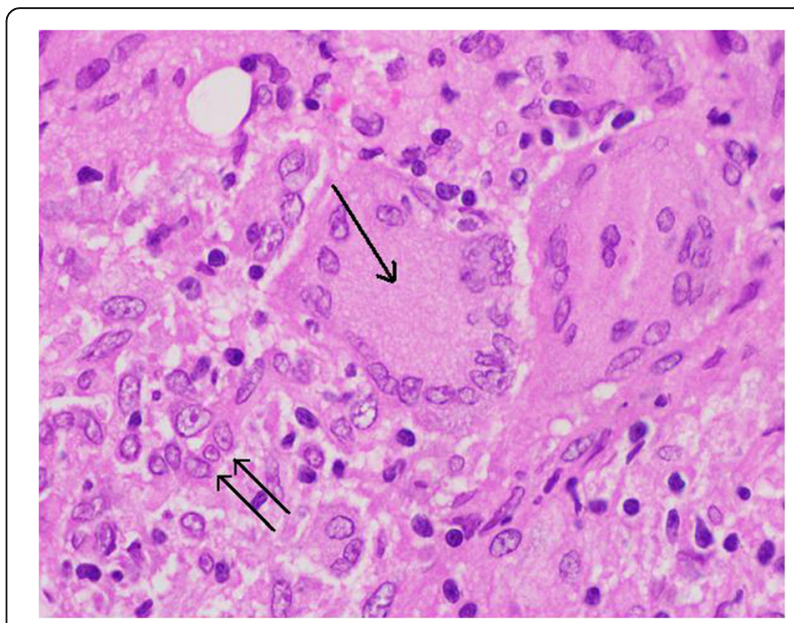

Fig. 2 Giant cell granuloma (single arrow) surrounded by multiple histiocytes (double arrow)

treatment (isoniazid, rifampicin, and ethambutol). She showed gradual improvement, the swelling subsided, and the wound healed completely; she received the antituberculous treatment for 1 year. At follow-up visits, she used her left forearm normally with full range of movement (Fig. 3). A repeat X-ray showed complete healing (Fig. 4)

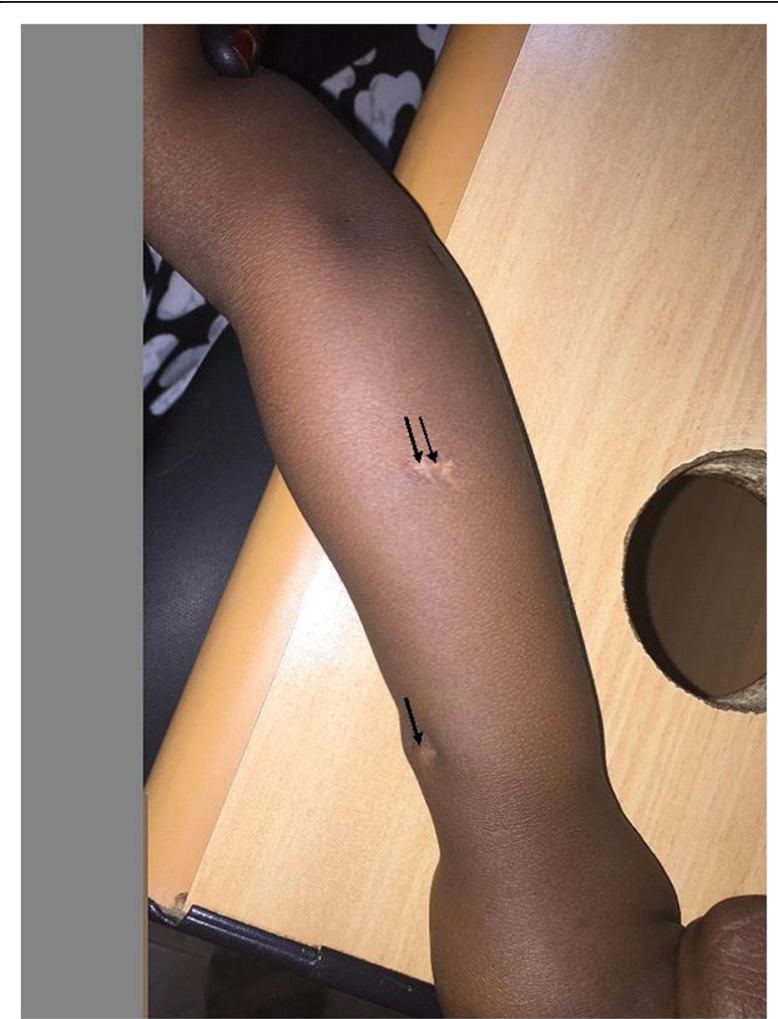

Fig. 3 Scar of the healed lesion (single arrow) and Bacillus Calmette-Guérin scar (double arrow) 


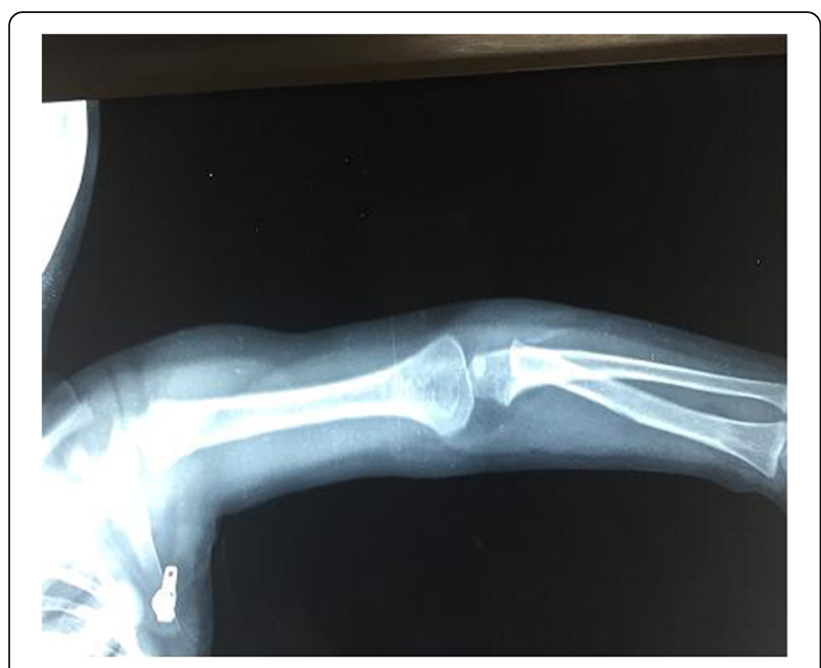

Fig. 4 A follow-up X-ray with complete disappearance of the lytic lesion

\section{Discussion}

The BCG vaccine was named after the two French investigators responsible for its original development in 1923 and has now been used for nearly 100 years in the prevention of tuberculosis [8]. Vitkova and associates studied post BCG vaccination adverse reactions in the period from 1981 to 1993, and demonstrated an elevated incidence of local and regional lymph node complications. In addition, bone and joint involvement following BCG vaccination at birth was reported as a new phenomenon [9].

The baby described here presented with swelling of her left arm following BCG vaccination; this is not surprising as the lesions tend to appear on the same side of the body as the vaccination [10]. Our case presented at the age of 3 months. The age of onset of BCG osteitis varies widely according to the reported cases in the literature. In a study from Iran the age varied from 4 to 36 months [11]. In a study of 222 children from Finland, Kröger and associates showed an age range of 0.25 to 5.7 years [3] and in a similar study the mean age was reported to be 11 months [12].

The diagnosis of osteitis after BCG vaccination in our case was established according to the criteria proposed by Foucard and Hjelmstedt in 1971 which include BCG vaccination in the neonatal period, period of less than 4 years between vaccination and symptom onset, no contact between the child and any adults with tuberculosis, a consistent clinical profile, and histopathology suggestive of tuberculosis [13]. Our case developed a bony lesion in the distal radius which is very rare. Tuberculosis of the hand and wrist is the rarest osteoarticular localization. It represents 2 to $4 \%$ of all the localizations of the musculoskeletal system [14].

In our case a prompt diagnosis of tuberculous osteitis of the radius was not made; again this is not surprising as the diagnosis is usually delayed because the lesions may be overlooked due to their rarity, the symptoms tend to develop slowly, and the primary course is fairly benign [10]. Timely diagnosis of BCG osteitis is important since antituberculous therapy is effective when initiated early in the course of disease.

The case described here had a normal CXR; only approximately one third of patients with tuberculosis of the bone have pulmonary involvement, making chest $\mathrm{X}$-ray screening less useful [15].

Treatment of BCG osteitis usually consists of both surgical intervention and antituberculous medication. However, pyrazinamide cannot be used because BCG is resistant to it [10]. The case described here received surgical evacuation as well as antituberculous treatment for 1 year without pyrazinamide with complete healing at follow-up visits. There was no demonstrable difference in the length of both forearms. According to the reported cases in the literature, the long-term evolution of most patients is favorable, and bone sequelae or growth deficit are described in only 3\% of the cases [3].

\section{Conclusions}

BCG osteitis, although rare, should be considered a possible complication of the BCG vaccination, and early diagnosis and treatment of this complication are necessary. Osteitis that has a fairly benign course in children should raise suspicion of a tuberculous origin, particularly if the disease does not respond favorably to conventional antibiotics. Despite this rare complication of the BCG vaccine, the use of the vaccine should be maintained in countries with a high incidence of tuberculosis, Sudan is no exception.

\section{Abbreviations}

BCG: Bacillus Calmette-Guérin; CRP: C-reactive protein; CXR: Chest X-ray; ESR: Erythrocyte sedimentation rate

\section{Acknowledgements}

The authors would like to thank the family of the child mentioned in this report for consent to report this case and use the images.

\section{Funding \\ There is no financial support for this case report.}

\section{Availability of data and materials}

Data and materials supporting this report are available in the records of the hospital where this patient was confined and can be requested directly from the corresponding author to some extent, without revealing patient identity.

\section{Authors' contributions}

AEMK and SI interpreted the patient data regarding the disease, designed the case report, and contributed in writing the manuscript. AA performed the histological examination of the tissue biopsy, and was a major contributor in writing the manuscript. MB reported the X-ray images and contributed in writing the manuscript. All authors read and approved the final manuscript.

Ethics approval and consent to participate Not applicable. 


\section{Consent for publication}

Written informed consent was obtained from the patient's legal guardian for publication of this case report and any accompanying images. A copy of the written consent is available for review by the Editor-in-Chief of this journal.

\section{Competing interests}

The authors declare that they have no competing interests.

\section{Publisher's Note}

Springer Nature remains neutral with regard to jurisdictional claims in published maps and institutional affiliations.

\section{Author details}

'Department of Paediatrics and Child Health, Faculty of Medicine, University of Khartoum, Khartoum, Sudan. ${ }^{2}$ Department of Pathology, State Ministry of Health, Khartoum, Sudan. ${ }^{3}$ Department of Radiology, Soba University Hospital, Khartoum, Sudan. ${ }^{4}$ Department of Paediatrics and Child Health, Faculty of Medicine, University of Khartoum and Soba University Hospital, P.O. Box 102, Khartoum, Sudan.

Received: 17 May 2017 Accepted: 8 September 2017

\section{Published online: 04 October 2017}

\section{References}

1. Hotokezaka H, Kitamura A, Matsumoto S, Hanazawa S, Amono S, Yamada T. Internalization of Mycobacterium bovis Bacillus Calmette-Guérin into osteoblast-like MC3T3-E1 cells and bone resorptive responses of the cells against the infection. Scand J Immunol. 1998:47:453-8.

2. Besnard M, Sauvion S, Offredo C, Gaudelus J, Gaillard JL, Veber F, et al. Bacillus Calmette-Guérin infection after vaccination of human immunodeficiency virusinfected children. Pediatr Infect Dis J. 1993;12:993-7.

3. Kröger L, Korppi M, Brander E, Kröger H, Wasz-Höckert O, Backman A, et al. Osteitis caused by bacille Calmette-Guérin vaccination: a retrospective analysis of 222 cases. J Infect Dis. 1995;172(2):574-6.

4. Vallejo JG, Ong LT, Starke JR. Tuberculous osteomyelitis of the long bones in children. Pediatr Infect Dis J. 1995;14:542-6.

5. Ibrahim SA, Omer MIA, Humeida TI. Median nerve compression following $B C G$ vaccination. A case report and literature review of complications of BCG vaccination. Sudan Med J. 1994;32(1):98-109.

6. Ulstrup JC, Jeansson S, Wiker HG, Harboe M. Relationship of secretion pattern and MPB70 homology with osteoblast specific factor 2 to osteitis following Mycobacterium bovis BCG vaccination. Infect Immun. 1995;63(2):672-5.

7. Wang MN, Chen WM, Lee KS, Chin LS, Lo WH. Tuberculous osteomyelitis in young children. J Pediatr Orthop. 1999;19(2):151-5.

8. Colditz GA, Berkey CS, Mosteller F, Brewer TF, Wilson ME, Burdick E, et al. The efficacy of bacillus Calmette-Guérin vaccination of newborns and infants in the prevention of tuberculosis: meta-analyses of the published literature. Pediatrics. 1995:96:29-35.

9. Vitkova E, Galliova J, Krepela K, Kubin M. Adverse reactions to BCG. Cent Eur J Public Health. 1995:3(3):138-41.

10. Peltola H, Salmi I, Vahvanen V, Ahlqvist J. BCG vaccination as a cause of osteomyelitis and subcutaneous abscess. Arch Dis Child. 1984;59:157-61.

11. Daneshjou KH, Farzan M, Giti MR, Zamani A. BCG Osteitis. Acta Med Iran 2004;42(1):73-7.

12. Castro-Rodriguez JA, Gonzalez R, Girardi G. Osteitis caused by bacille Calmette-Guerin vaccination: an emergent problem in Chile? Int J Tuberc Lung Dis. 1997;1(5):417-21.

13. Yamada AF, Pellegrini JB, Cunha LM, Fernandes ARC. Osteitis after BCG vaccination. J Bras Pneumol. 2009:35(3):285-9.

14. Sbai MA, Benzarti S, Bouzaidi K, Sbei F, Maalla R. A rare localization of tuberculosis of the wrist: The scapholunate joint. Int J Mycobacteriol. 2015:4:161-4.

15. Aghoutane EM, Salama T, El Fezazi R. Tuberculosis of the wrist in children: A rare manifestation. Int J Mycobacteriol. 2017:6(1):106-7.

\section{Submit your next manuscript to BioMed Central and we will help you at every step:}

- We accept pre-submission inquiries

- Our selector tool helps you to find the most relevant journal

- We provide round the clock customer support

- Convenient online submission

- Thorough peer review

- Inclusion in PubMed and all major indexing services

- Maximum visibility for your research

Submit your manuscript at www.biomedcentral.com/submit 